\title{
Effect of Gender and Body Weight on Postprandial Glucose and Lipid Metabolism in Adults with Type 2 Diabetes
}

\author{
Mustapha Diaf, 'Boumediene Meghit Khaled, ' Houari Hadj Habib, ' Slimane Belbraoued' \\ 'Department of Biology, Faculty of Natural and Life Sciences, Dillali Liabes University, Sidi-bel-Abbes, Algeria.
}

\section{ABSTRACT}

Introduction: The magnitude of the healthcare problem of type-2-diabetes increases according to its association with several risk factors for cardiovascular diseases such as obesity and dyslipidemia.

Methods: This study took place in the north-western region of Algeria. We aimed to assess the effect of body weight and gender on postprandial lipid and glucose in type-2-diabetes patients. 93 diabetic patients (age 55.65 \pm 13.81 years) were studied. Anthropometric parameters and body mass index (BMI) were measured. Fasting and postprandial (PP) glucose and lipid (total cholesterol, HDLcholesterol, LDL-cholesterol, triglycerides, apo A-I and apo B) profiles were evaluated.

Results: There were a positive correlation between postprandial glucose and BMI in women $\left(\mathrm{r}^{2}=\right.$ 0.041). Negative correlation with BMI was noticed for PP TG in both males $\left(r^{2}=0.011\right)$ and females $\left(r^{2}=0.021\right)$. A significant difference $(p=0.019)$ was observed for PP HDL-c in women $(0.39 \pm 0.10$ $\mathrm{g} / \mathrm{L}$ vs. men $0.33 \pm 0.12 \mathrm{~g} / \mathrm{L}$ ) and also for PP apo A-I (women: $1.33 \pm 0.27 \mathrm{~g} / \mathrm{L}$ vs. men: $1.09 \pm 0.34$ $\mathrm{g} / \mathrm{L} ; \mathrm{p}=0.0003$ ). According to gender and weight groups, our results indicated that female gender and overweight are associated with elevated PP HDL-c and PP apo A-I levels. However, obesity in women is related to high concentration of PP TG.

Conclusions: The present study suggests that gender difference and weight classes are important factors that contribute to determining the postprandial responses, both for glucose and lipids, in type 2 diabetic patients.

Keywords: gender difference; postprandial dyslipidemia; type 2 diabetes; weight groups.

\section{INTRODUCTION}

In nearly the whole developed and developing countries through the world, type 2 diabetes is continuing to be an increasing public health burden. The worldwide prevalence of diabetes among adults (aged 20-79 years) will increase from $6.4 \%$ in 2010 to $7.7 \%$ by $2033 .{ }^{1}$

Higher vascular disease risks, including cardiovascular diseases (CVD), atherosclerosis, myocardial infarction, stroke and peripheral vascular disease are commonly associated with type 2 diabetes in adults. ${ }^{2,3}$ Patients with type 2 diabetes were seen to manifest symptoms

Correspondence: Mustapha Diaf, Department of Biology, Faculty of Natural and Life Sciences, Diillali LIABES University, Sidi-belAbbes, Algeria. Email : diafmustapha@gmail.com, Phone No: +213696495465 . 
of hypertension, abnormal lipemia, obesity, lack of physical exercise and blood sugars which were not properly controlled. By systematic control of these risk factors, diabetic patients may protract the development of heart disease. Change of lifestyle is paramount in CVD strategies in diabetes management. 4,5 The exceeding of body weight associated with glucose intolerance and/or type 2 diabetes is characterized by hyperinsulinaemia, peripheral resistance to the action of insulin, hypertriglyceridaemia, decreased high-density lipoprotein cholesterol (HDL-c) and other lipid and carbohydrate changes. ${ }^{6,7}$ While a significant association between coronary artery disease and fasting hypertriglyceridaemia has been found in diabetes mellitus according to several studies, ${ }^{8,9}$ and considering that we are spending the most part of the day in the postprandial phase, it was about thirty years ago, when Zilversmit suggested that postprandial lipemia may have a role in atherogenesis and other cardiovascular problems. ${ }^{10}$

Currently, both type 2 diabetes and obesity have been associated with exaggerated postprandial lipemia and glycaemia. Postprandial lipid and glucose metabolism states have been investigated under some standardized circumstances, such as standardized fatty meal or an oral glucose tolerance test, which may not reflects exactly the free-living daylong situation. ${ }^{11,12}$

However, direct comparison study between groups according to their body weight with or without diabetes based on the normal daily diet are scarce. ${ }^{13,14}$

Hence, the major aim of our study was to investigate the effects of body weight and gender difference on postprandial lipid and glucose responses in adult patients with type 2 diabetes.

\section{METHODS}

\section{Patients and Study Design}

Our study was carried out during five months, from March to July 2013, and covered a total of 93 adult diabetic patients (35 men and 58 women). This work took place in two cities located in the Northwestern region of Algeria; Sidi-Bel-Abbès city: Public Establishment of Proximity Health (diabetes centre of Ex Gambetta and Mostefa Ben Brahim polyclinic) and Mascara city (Meslem Tayeb Hospital). Informed consent was obtained from each participant before initiating the study protocol.

The average of diabetes duration was $5.15 \pm 3.53$ years (5.31 \pm 3.11 years for males vs. $5.11 \pm 3.78$ years for females). All adult patients with type 2 diabetes, following an oral and/or dietary treatment and free from any degenerative health complication were solicited to take part in our study. Patients treated with insulin and pregnant women were excluded from this study.

\section{Anthropometric Measurements}

The measurements were taken in the morning for weight, height and waist circumference (WC) according to the recommendations of the World Health Organization (WHO). ${ }^{15}$ The body weight (in kilograms) was measured using an electronic balance (TS-2003A: $360 \mathrm{lb}$, Capacity: $180 \mathrm{Kg}$, Graduations $0.1 \mathrm{Kg}$ ). The body height was measured with a body meter (Seca 206, Germany; Measuring range: $0-220 \mathrm{~cm}$, Graduation Length: 1 $\mathrm{mm}$ ) then the body mass index (BMI) was defined as follow: BMI $\left(\mathrm{kg} / \mathrm{m}^{2}\right)=$ weight $(\mathrm{kg}) /$ height $^{2}\left(\mathrm{~m}^{2}\right)$.

The WC was measured with a measuring tape (Maximum: $150 \mathrm{~cm}$, Graduation Length: $1 \mathrm{~mm}$ ), we gently tightened the tape around the patient's abdomen roughly in line with the navel without depressing the skin.

\section{Blood Pressure Measurement}

The blood pressure was taken precisely in the morning using OMRON M3 Digital Automatic Blood Pressure Monitor (Omron Healthcare., Ltd. Kyoto, Japan).

Each patient was seated in a congruous position for at least five minutes, with good back support and arms being folded at the level of the heart. The feet should touch the floor and legs should not be crossed. The procedure was explained to each patient with specific instructions not to talk prior or during the procedure.

\section{Biological Parameters}

For the fasting period, blood samples were drawn from each patient $12 \mathrm{~h}$ after an overnight fast for glucose and lipid profile measurement. However, concerning the postprandial metabolism, blood samples were taken $2 \mathrm{~h}$ after the beginning of breakfast for glucose and 3-4 $\mathrm{h}$ for total cholesterol (TC), HDL-c, low density lipoprotein cholesterol (LDL-c), triglycerides (TG), apolipoproteins A1 (apo A-I) and apolipoproteins B (apo B).

According to the proposal for standardization of postprandial studies established by Lairon et al. 2007 the morning is the ideal time sampling. ${ }^{16}$ The postprandial peak of lipids is around $3 \mathrm{~h}$ after the beginning of meals. 17

To determine the serum concentration of glucose, total cholesterol, HDL-c and triglycerides, both in the fasting state or the postprandial state, the enzymatic colorimetric methods (Spinreact Reagents, Spain) 
were used. 18 Direct determination of serum LDL-C level was performed without the need for any pretreatment or centrifugation steps. However, the $\mathrm{HbA} 1 \mathrm{c}$ concentration value was determined using an ion exchange resin separation.

For the measurement of apo A-I and B in human serum, turbidimetric tests (Spinreact Reagents, Spain) were used. Insoluble complexes occur after specific reaction between apo A-I and apo $B$ antibodies and serum sample containing apo $A-I$ and apo $B$, which induce a change in the absorbance that can be quantified by comparison with known calibrators for the concentration of apo A-I and apo B.

\section{Other Information}

A questionnaire for gathering socio-professional data, lifestyle and eating behaviour was done by patients with a three days food diary.

Drugs prescribed and pharmacological measures followed by our adult diabetic patients were collected from their medical records.

According to information derived from the medical reports of each patient, metformin alone $(38.70 \%)$ or in combination with glimepiride (55.91\%), followed by sulfonylureas $(5.37 \%)$ were the most common antidiabetic agents prescribed for our patients. However, the most commonly prescribed drugs for cardiovascular co-morbidities were Statins (54.83\%), precisely Fluvastatin \& Atorvastatin and then lastly antiplatelet drugs. Patients who continue to use Statins during the period of our study were excluded from our sample. Patients are informed not to use oral medications during the day of sampling both for the fasting glucose and postprandial glucose.

\section{Statistical Analysis}

All data were processed and analyzed through SPSS 20.0 (Statistical Package for the Social Sciences, IBM Corporation; Chicago, IL. August 2011). Results are expressed as Means \pm Standard Deviations, the paired student t-test for independent samples was used for comparing this means values with statistical significance set at $\mathrm{p}=0.05$. BMl and waist girth were correlated with some postprandial and fasting lipid and glucose levels using the simple linear regression with a confidence interval of $95 \%$.

\section{RESULTS}

\section{Patient's Characteristics}

A total of 93 adult diabetic patients were included in our study, the majority of the participants was females $(62.36 \%$ vs. $37.64 \%$ males). The prevalence of normal weight, overweight and obesity was $32.25 \%, 41.93 \%$ and $25.81 \%$, respectively (Table 1 ).

The average of age was $55.65 \pm 13.81$ years. Males and females had approximately similar age $(p=$ $0.0700)$. Men had significantly a higher weight $(p=$ 0.001 ) and height ( $p=0.0002$ ) (Table 2). However, the body weight was sharply higher compared to the ideal body weight (Lorentz formula) both in male (81.87 $\pm 11.86 \mathrm{Kg}$ vs. $66.84 \pm 4.49 \mathrm{Kg}$ ) and in female $(74.07 \pm 9.78 \mathrm{Kg}$ vs. $59.12 \pm 4.96 \mathrm{Kg})$. The gender had no significant effect ( $p=0.963$ ) on the mean BMI between male $\left(27.45 \pm 5.54 \mathrm{Kg} / \mathrm{m}^{2}\right)$ and female $(27.49$ $\pm 3.86 \mathrm{Kg} / \mathrm{m}^{2}$ ). Five patients ( 3 men and 2 women) had morbid obesity BMI $\geq 35 \mathrm{Kg} / \mathrm{m}^{2}$. Android obesity has been studied using the waist circumference, which was higher in both genders compared to standards although the difference between genders was not significant ( $p$ $=0.381$ ).

The Systolic blood pressure was observed to be slightly high in all participants without a significant difference ( $p=0.995$ ) between male and female. Furthermore, results of Diastolic blood pressures were not significantly related to the patient's gender.

\section{Plasma Concentrations in the Fasting State}

The blood concentration in $\mathrm{HbA} 1 \mathrm{c}$ indicated that no significant difference existed between male and female ( $p=0.865)$ nonetheless, the levels of $\mathrm{HbA} 1 \mathrm{c}$ were high for all the participants reveal abnormal results levels in blood sugar rates over a period of weeks or months (Table 2). 


\begin{tabular}{|c|c|c|c|c|}
\hline & & \multicolumn{2}{|c|}{ Gender (frequency) } & \multirow{2}{*}{ Total } \\
\hline & & Male & Female & \\
\hline \multirow{3}{*}{ Weight classes } & Normal Weight & $13(13.97 \%)$ & 17 (18.27\%) & $30(32.25 \%)$ \\
\hline & Overweight & $12(12.90 \%)$ & $27(29.03 \%)$ & $39(41.93 \%)$ \\
\hline & Obese & $10(10.76 \%)$ & $14(15.05 \%)$ & $24(25.81 \%)$ \\
\hline Total & & 35 (37.64\%) & $58(62.36 \%)$ & $93(100.0 \%)$ \\
\hline
\end{tabular}

Table 2. Anthropometric and biological characteristics of the participants.

\begin{tabular}{|c|c|c|c|}
\hline Parameters & Men (35) mean \pm Std. & $\begin{array}{l}\text { Women (58) } \\
\text { mean } \pm \text { Std. }\end{array}$ & $\boldsymbol{P}$ values for $t$-test \\
\hline Age (year) & $56.37 \pm 15.87$ & $55.22 \pm 12.53$ & 0.700 \\
\hline Diabetes Duration (year) & $5.31 \pm 3.11$ & $5.11 \pm 3.78$ & 0.792 \\
\hline Weight (Kg) & $81.87 \pm 11.86$ & $74.07 \pm 9.78$ & 0.001 \\
\hline Height $(\mathrm{cm})$ & $173.02 \pm 6.11$ & $164.43 \pm 5.85$ & 0.000 \\
\hline Ideal Body Weight $(\mathrm{Kg})^{*}$ & $66.84 \pm 4.49$ & $59.12 \pm 4.96$ & 0.000 \\
\hline Waist Circumference $(\mathrm{cm})$ & $98.38 \pm 9.52$ & $96.47 \pm 10.48$ & 0.381 \\
\hline BMI $\left(\mathrm{Kg} / \mathrm{m}^{2}\right)$ & $27.45 \pm 4.54$ & $27.49 \pm 3.86$ & 0.963 \\
\hline Systolic Pressure (mmHg) & $13.04 \pm 1.86$ & $13.04 \pm 1.69$ & 0.995 \\
\hline Diastolic Pressure (mmHg) & $7.62 \pm 0.97$ & $7.47 \pm 0.98$ & 0.462 \\
\hline Heartbeat & $82.94 \pm 9.90$ & $73.24 \pm 5.82$ & 0.000 \\
\hline HbAlc (\%) & $7.45 \pm 1.65$ & $7.50 \pm 1.14$ & 0.865 \\
\hline F glucose $(\mathrm{g} / \mathrm{L})$ & $1.66 \pm 0.70$ & $1.46 \pm 0.53$ & 0.131 \\
\hline $\mathrm{F}$ TC $(\mathrm{g} / \mathrm{L})$ & $1.67 \pm 0.37$ & $1.63 \pm 0.33$ & 0.663 \\
\hline F HDL-c (g/L) & $0.37 \pm 0.11$ & $0.38 \pm 0.09$ & 0.372 \\
\hline F LDL-c (g/L) & $1.02 \pm 0.33$ & $1.01 \pm 0.31$ & 0.841 \\
\hline F TG $(\mathrm{g} / \mathrm{L})$ & $1.30 \pm 0.55$ & $1.42 \pm 0.65$ & 0.387 \\
\hline PP glucose (g/L) & $2.28 \pm 1.07$ & $2.19 \pm 0.73$ & 0.637 \\
\hline PP TC (g/L) & $1.79 \pm 0.53$ & $1.78 \pm 0.39$ & 0.970 \\
\hline PP HDL-c (g/L) & $0.33 \pm 0.12$ & $0.39 \pm 0.10$ & 0.019 \\
\hline PP LDL-c (g/L) & $1.15 \pm 0.47$ & $1.09 \pm 0.34$ & 0.465 \\
\hline
\end{tabular}




\begin{tabular}{|c|c|c|c|}
\hline PP TG (g/L) & $1.69 \pm 1.10$ & $1.53 \pm 0.69$ & 0.394 \\
\hline PP apo A-I (g/L) & $1.09 \pm 0.34$ & $1.33 \pm 0.27$ & 0.000 \\
\hline PP аро B (g/L) & $0.89 \pm 0.31$ & $0.96 \pm 0.41$ & 0.413 \\
\hline
\end{tabular}

BMI: Body Mass Index; F TC: Fasting Total Cholesterol; F HDL-c: Fasting HDL Cholesterol; F LDL-c: Fasting LDL Cholesterol; F TG: Fasting Triglycerides; PP TC:Posprandial Total Cholesterol; PP HDL-c:Posprandial HDL Cholesterol; PP LDL-c:Posprandial LDL Cholesterol; PP TG:Posprandial Triglycerides; PP apo A-I:Posprandialapo A-I; PP apo B:Posprandialapo B

* Lorentz formula

During the fasting period there were no significant differences for glucose or any lipid parameters (TC, HDL-C, LDL-c and TG) between male and female.

\section{Plasma Concentration in the Postprandial State}

We observed some postprandial lipid abnormalities in the investigated patients particularly of HDL-c and apo A-I. Postprandial (PP) HDL-c was significantly higher among women than men $10.39 \pm 0.10 \mathrm{~g} / \mathrm{L}$ vs. 0.33 $\pm 0.12 \mathrm{~g} / \mathrm{L} ; \mathrm{p}=0.019)$ and also a significant high concentration of PP apo A-I in women (1.33 \pm 0.27 vs. $1.09 \pm 0.34$ in men). Contrariwise, there was no inter-gender variability for postprandial glucose or other postprandial lipid parameters.

\section{Correlations}

Among adult male diabetic patients, BMI was positively correlated to $\mathrm{HbA} 1 \mathrm{c}$ values $\left(r^{2}=0.077\right)$ but negatively to PP glucose $\left(r^{2}=0.013\right)$. In the opposite, in women, $\mathrm{BMI}$ is inversely correlated to $\mathrm{HbA} 1 \mathrm{c}\left(\mathrm{r}^{2}=0.046\right)$ and positively to PP glucose $\left(r^{2}=0.041\right)$ (Figure 1$)$.

Concerning the postprandial lipid parameters, PP HDL-C is linked to the $\mathrm{BMI}$ in both gender groups particularly in men ( $r^{2}=0.099$ vs. $r^{2}=0.009$ in women) (Figure 2). However, inversely relations were noticed between PP TG and BMI $\left(r^{2}=0.011\right.$ in male vs. $r^{2}=0.021$ in female).

As indicated in figure 3. Correlation between PP TG and waist girth, which represents a good indicator of android obesity, was positive in men $\left(r^{2}=0.026\right)$ and negative in women $\left(r^{2}=0.044\right)$.

Taking into consideration the gender and weight groups (normal weight, overweight and obese), our results indicated that female gender and overweight are associated with elevated PP HDL-c and PP apo A-I levels. However, obesity in women is related to high concentration of PP TG (Figure 4). 


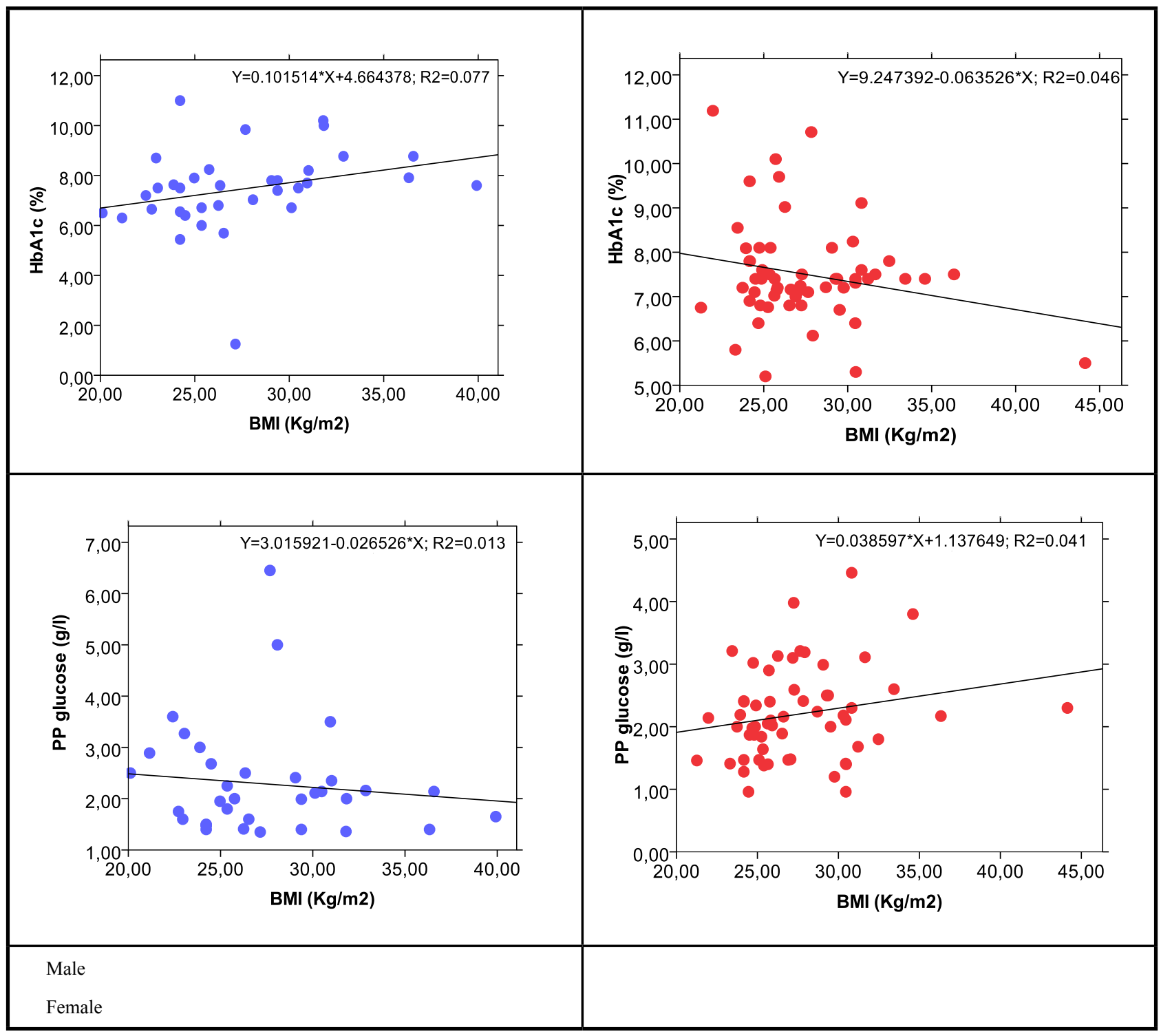

Figure 1. Effect of BMI on HbA1c and postprandial glucose among males and females. 


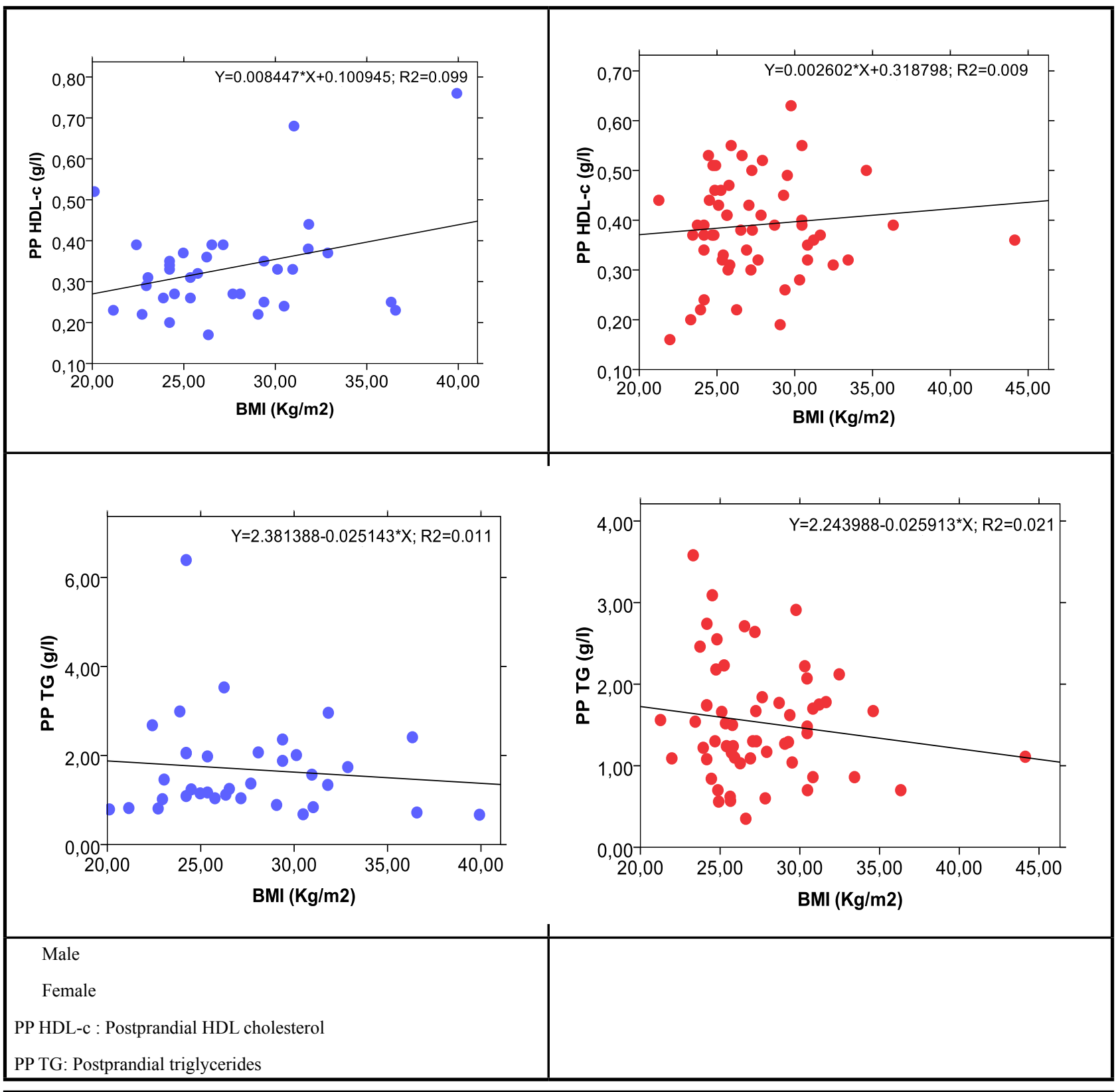

Figure 2. Effect of BMI on postprandial HDL cholesterol and triglycerides among males and females. 


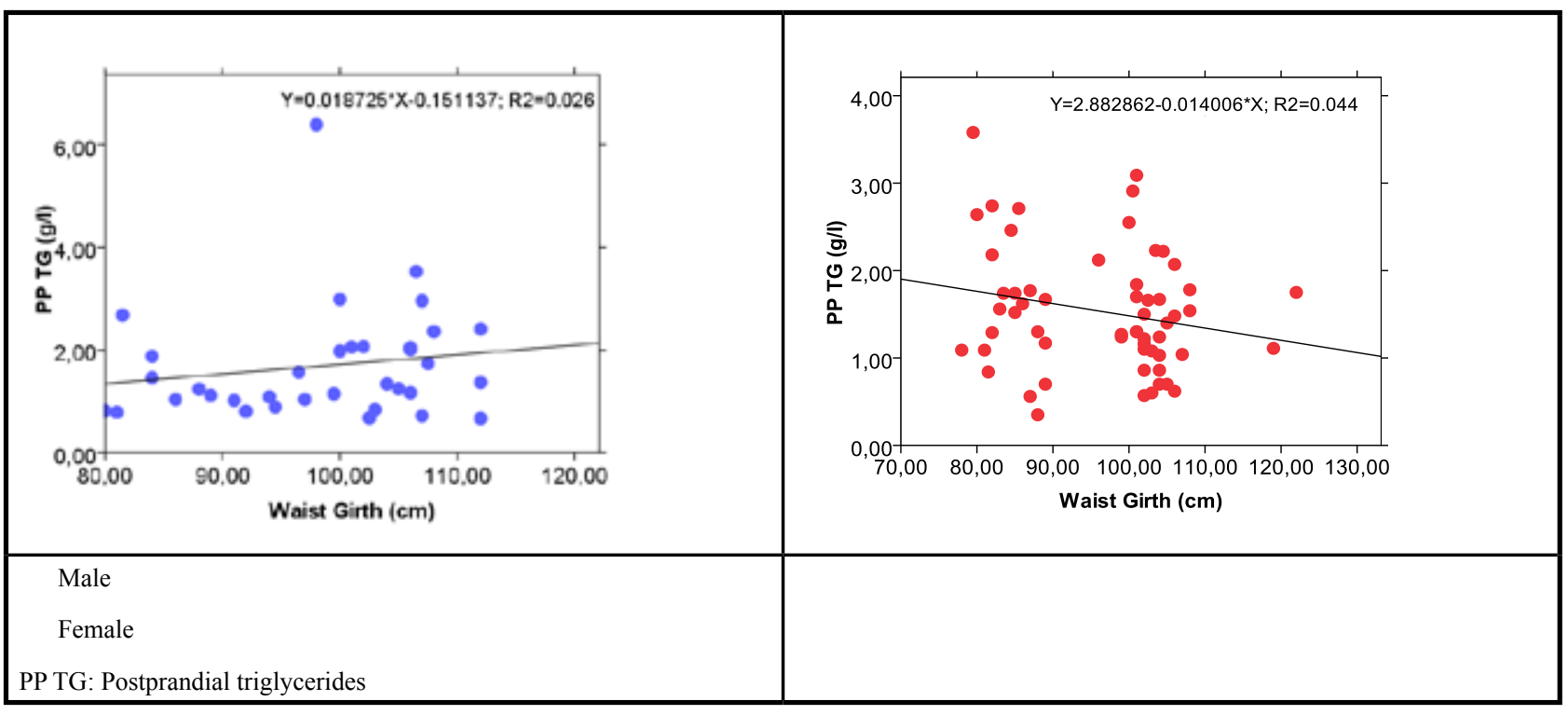

Figure 3. Effect of waist circumference on postprandial triglycerides among males and females.

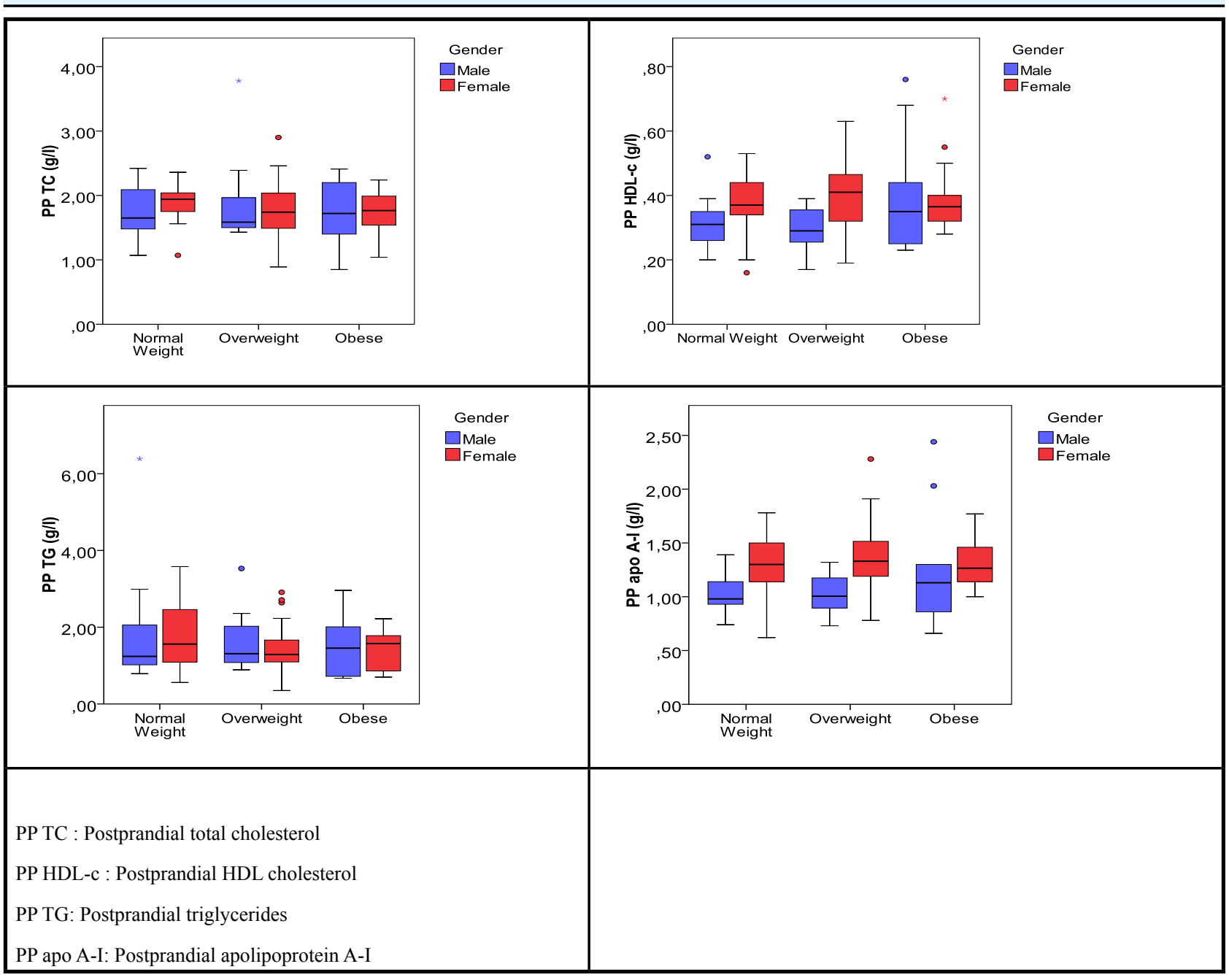

Figure 4. Postprandial lipemia according to weight classes (normal weight, overweight and obese) among diabetes patients. 


\section{DISCUSSION}

The worldwide prevalence of type 2 diabetes is genuinely increasing, the likeliest explanation is, undoubtedly, the increasing incidence of this metabolic disease, but also the better health care and the improving longevity of people with diabetes. ${ }^{1,2,4}$ It is noteworthy that the increasing cardiovascular mortality and morbidity in type 2 diabetic patients stem from the association between the diabetic disease and other risk factors such as age, ${ }^{19}$ diet, physical activity, 20 obesity, body fat distribution, hypertension and lipid abnormalities. By the time they were first diagnosed with diabetes, most of adult diabetic had already experienced these diabetic complications. ${ }^{21}$

A consistent body of data demonstrates a robust association between postprandial glucose and postprandial lipid levels, on one hand, and cardiovascular risk, coronary atherosclerosis and carotid artery intimal thickness on the other hand. ${ }^{10,22}$ The importance of the postprandial state against the fasting period comes from the fact that we spend most of our waking hours in the postprandial state.

In this study we aimed to investigate the effects of body weight and gender difference on postprandial lipid and glucose responses in adult patients with type 2 diabetes.

Many studies have reported on the increasing use of $\mathrm{HbA} 1 \mathrm{c}$ and fasting plasma glucose to monitor longterm glycemic control in diabetic patients. ${ }^{23-24}$ However, according to Monnier et al., low HbA1c levels are due to the contribution of PP glucose. ${ }^{25}$ With HbA1c < $7.3 \%$, the contribution of PP glucose is $70 \%$. Whereas, with $\mathrm{HbA} 1 \mathrm{c}$ levels between $7.3 \%$ and $8.4 \%$, the contribution of PP glucose is at $50 \%$.

Our results showed no significant difference $(p=0.865)$ in $\mathrm{HbA} 1 \mathrm{c}$ levels between men and women. The same results were found by Calisti \& Tognetti. ${ }^{26}$ A positive correlation was observed between $\mathrm{BMI}$ and $\mathrm{HbA} 1 \mathrm{c}$ level in men, conversely a negative correlation was noticed in women. A Sudanese study showed no correlation between $\mathrm{HbA} 1 \mathrm{c}$ and $\mathrm{BMI}$ both in men and women. ${ }^{27}$ The same results were found by Longo-Mbenza et al. ${ }^{28}$ Paradoxically, there was a positive correlation between $\mathrm{HbA} 1 \mathrm{c}$ levels and BMI in a Japanese population. ${ }^{29}$

Gender had no effect on glucose concentration neither in the fasting state $(p=0.131)$ nor in the postprandial state $(p=0.637)$. The same findings were obtained in many studies. ${ }^{13,30}$

Concerning the fasting blood glucose levels, there was a positive but non-significant correlation between blood glucose and BMI among male subjects $\left(r^{2}=0.020\right.$, $p=0.412)$. However, in the postprandial state, the correlation between these variables was however negative but not significant $\left(r^{2}=0.013, p=0.520\right)$. In females, the correlation was negative in the fasting state and positive in the postprandial state. Our findings agree with those of Bakari et al. ${ }^{31}$ Other studies showed mixed results. ${ }^{32,33}$

In this investigation, lipids concentrations were minimally different between men and women for the measurements performed in the fasting state. No significant difference between the two groups of gender was noticed for TC, HDL-C, LDL-c and TG levels which are not in accordance with results of many studies. ${ }^{34,35}$ Somewhat, similar to the result of Mengesha. ${ }^{36}$

Despite similar fasting lipid levels, a lower but not significant PP TG response has been reported in women than men in the current study. These agree with previous results that reported higher postprandial levels of triglycerides in men than women, ${ }^{37}$ and disagree with those found by Amrane \& Khaled. ${ }^{13}$ The postprandial lipid response is the state following the food intake but situated before the post-absorptive state. Free fatty acids, packaged into large triglyceride rich particles together with apo B, are absorbed by intestine during this phase. ${ }^{38}$ In the present study, gender differences were also observed in postprandial HDL-c response. Men being characterized by a significant low postprandial HDL-c level compared with women.

In type 2 diabetes patients, there is frequently a strong interrelationship between the hypertriglyceridaemia and low HDL-c. Hypertriglyceridaemia induces an increase in lipid exchange which leads to produce triglyceride enriched HDL hydrolyzed afterwards into small dense HDL particles by hepatic lipases. The small dense HDL particles newly produced are rapidly cleared from the blood circulation. ${ }^{39}$

A significant high concentration of PP apo A-I was observed in female diabetic patients comparing to males. However, no significant difference between male and female was found about PP apo B.

Measuring apo B level, the moiety of LDL, and apo A-I concentration, the major protein found in HDL-C can play an important role in the clinical assessment and monitoring of CVD and stroke. In a recent study, including a very large sample, comparing nonfasting lipids, lipoproteins, and apolipoproteins in individuals with and without diabetes, no statistically significant differences in postprandial apo $B$ concentrations were found. ${ }^{40}$ When Jungner et al. studied apo B and A-I values in 147576 males and females, according to the WHO standards, they found that the $95 \%$ interval for 
apo A-I was between 0.99 and $1.84 \mathrm{~g} / \mathrm{L}$ in males and between 1.09 and $2.04 \mathrm{~g} / \mathrm{L}$ in females. However, in the same study, the median apo $\mathrm{B}$ concentrations in adult females were 0.92-1.38 g/L and 0.99-1.36 g/L in males, including all ages. ${ }^{41}$

The present study clearly demonstrates a high PP TG response in both males and females type 2 diabetes individuals compared to the fasting state. Comparing to some previous data, ${ }^{13,42}$ a negative correlation between BMI and PP TG was observed in the present study in both genders, which agree with the result of Reznik et al. ${ }^{43}$ This can be explained, if we take into account that the part of obese patients in our sample was about $25 \%$ and nearly $80 \%$ of them, had BMI < $35 \mathrm{Kg} / \mathrm{m}^{2}$ (morbid obesity) and the extensive use of Statins (Fluvastatine \&Atorvastatine), in the history of our patients, which are likely to reduce triglycerides and retinylpalmitate over $30 \%$ during the postprandial state as reported by Parhoferet al. ${ }^{44}$ These drugs are known to increase the number of LDL receptors and improving removal of triglyceride-rich lipoproteins remnants in the postprandial state. Statins tend to induce a modest lowering of plasma triglycerides. This is likely to be due to an inhibition of very low density lipoproteins (VLDL) synthesis. ${ }^{45}$ This inhibition may also explain the proportional relation between PP HDL-C and BMI.

It is known that female gender is generally associated with an increasing activity of lipoproteins lipase which may predict the PP HDL-c accumulation as observed in our study and this for all weight groups. This finding, concerning the relationship between female gender and PP HDL-c, can also be a good explanation for the high postprandial accumulation of apo A-I in women. But, even though the apo A-I is the major lipoproteins found in HDL-c as was cited by many authors, 46,47 it has no statistically association with cardiovascular events.

\section{CONCLUSIONS}

People with type 2 diabetes have a greater chance of developing serious complications and health problems, especially if their disease is associated with other risk factors like overweight, obesity and postprandial dyslipidemia. In the same context, there is a gender difference in postprandial metabolic responses. Avoiding postprandial responses abnormalities and diabetes as a result, requires a good mastering of body weight taking into consideration the physiological differences between males and females.

\section{ACKNOWLEDGEMENTS}

We are very grateful to all the members of the House of diabetes patients and Mostefa Ben Brahim polyclinic in Sidi-Bel-Abbès city and the medical staff of MeslemTayeb Hospital in Mascara city. The authors declare that there is no conflict of interest.

\section{REFERENCES}

1. Shaw JE, Sicree RA, Zimmet PZ. Global estimates of the prevalence of diabetes for 2010 and 2030. Diabetes Res Clin Pract. 2010; 87:4-14.

2. Morrish NJ, Wang SL, Stevens LK, Fuller JH, Keen H. Mortality and causes of death in the WHO multinational study of vascular disease in diabetes. Diabetologia. 2001; 44:S14-S21.

3. Roglic G, Unwin N, Bennett PH, Mathers C, Tuomilehto J, Nag S, et al. The burden of mortality attributable to diabetes: Realistic estimates for the year 2000. Diabetes Care. 2005; 28:2130-5.

4. Gaede P, Vedel P, Larsen N, Jensen GV, Parving HH, Pedersen $\mathrm{O}$. Multifactorial intervention and cardiovascular disease in patients with type 2 diabetes. N Engl J Med. 2003; 348:383-93.

5. Zimmet PZ, Alberti G. The Metabolic Syndrome: Perhaps an Etiologic Mystery but Far From a Myth-Where Does the International Diabetes Federation Stand?. Medscape Diabetes \& Endocrinology. 2005; 7.
6. Reaven GM. The insulin resistance syndrome: definition and dietary approaches to treatment. Annu Rev Nutr. 2005; 25:391-406.

7. Weiss R, Dufour S, Taksali SE, Tamborlane WV, Petersen $\mathrm{KF}$, Bonadonna RC, et al. Prediabetes in obese youth: a syndrome of impaired glucose tolerance, severe insulin resistance, and altered myocellular and abdominal fat partitioning. Lancet. 2003; 362:951-7.

8. Murad MH, Hazem A, Coto-Yglesias F, Dzyubak S, Gupta S, Bancos I, et al. The association of hypertriglyceridemia with cardiovascular events and pancreatitis: a systematic review and meta-analysis. BMC Endocrine Disorders. 2012; 12:2.

9. Miller M, Stone NJ, Ballantyne C, Bittner V, Criqui $\mathrm{MH}$, Ginsberg HN, et al. Triglycerides and Cardiovascular Disease: A Scientific Statement From the American Heart Association. Circulation. 2011; 123:2292-333.

10. Zilversmit DB. Atherogenesis: A postprandial phenomenon. Circulation. 1979; 60:473-85. 
11. Ntyintyane LM, Panz VR, Raal FJ, Gill GV. Postprandial lipaemia, metabolic syndrome and LDL particle size in urbanised South African blacks with and without coronary artery disease. Q J Med. 2008; 101:111-9.

12. Monnier L, Colette C, Owens D. Postprandial and Basal Glucose in Type 2 Diabetes: Assessment and Respective Impacts. Diabetes Technol Ther. 2011; 13:S25-S32.

13. Amrane N, Khaled MB. Effect of Overweight and Obesity on Postprandial Lipemia among the Subjects with Type 2 Diabetes. J Diabetes Metab. 2012; 3:178.

14. Raj S, Rajasekharan C, Jayakumar B. Postprandial hypertriglycridaemia in type 2 diabetic subjects. Int J Diab Dev Ctries. 2006; 26:160-2.

15. World Health Organization (WHO). The WHO STEPwise approach to chronic disease risk factor surveillance. Switzerland; Geneva: World Health Organization; 2005.

16. Lairon D, Lopez-Miranda J, Williams C. Methodology for studying postprandial lipid metabolism. Eur J Clin Nutr. 2007; 61:1145-61.

17. Dubois C, Beaumier G, Juhel C, Armand M, Portugal H, Pauli AM, et al. Effects of graded amounts (0-50 g) of dietary fat on postprandial lipemia and lipoproteins in normolipidemic adults. Am J Clin Nutr. 1998; 67:31-8.

18. Hans Ulrich B. Methods of enzymatic analysis. New York \& London. Verlag Chemie Weinheim Academic Press; 1974.

19. Edward G, Lakatta MD. Age-associated Cardiovascular Changes in Health: Impact on Cardiovascular Disease in Older Persons. Heart Failure Reviews.2002; 7:29-49.

20. Wing RR, Hill JO. Successful weight loss maintenance. Annu Rev Nutr. 2001; 21:323-41.

21. UK Prospective Diabetes Study (UKPDS) Group. Effect of intensive blood-glucose control with metformin on complications in overweight patients with type 2 diabetes (UKPDS 34). Lancet.1998; 352:854-65.

22. Cavalot F, Petrelli A, Traversa M, Bonoma K, Fiora E, Conti $\mathrm{M}$, et al. Postprandial blood glucose is a stronger predictor of cardiovascular events than fasting blood glucose in type 2 diabetes mellitus. J Clin Endocrinol Metab. 2006; 91:813-9.

23. Rohlfing CL, Wiedmeyer H, Little RR, England JD, Tennill A, Goldstein DE. Defining the relationship between plasma glucose and HbA1c: Analysis of glucose profiles and $\mathrm{HbA1c}$ in the diabetes control and complications trial. Diabetes Care. 2002; 25:275-8.

24. Selvin E, Marinopoulos S, Berkenblit G, Rami T, Brancati FL, Powe NR, et al. Meta-Analysis: Glycosylated Hemoglobin and Cardiovascular Disease in Diabetes Mellitus. Ann Intern Med. 2004; 141:421-31.

25. Monnier L, Lapinski H, Colette C. Contributions of Fasting and Postprandial Plasma Glucose Increments to the Overall Diurnal Hyperglycemia of Type 2 Diabetic Patients: Variations with increasing levels of HbA1c. Diabetes Care. 2003; 26:881-5.

26. Calisti L, Tognetti S. Measure of glycosylated hemoglobin. Acta Biomed. 2005; 76:59-62.
27. Abbadi OS, Bakheit KH, Abdel Rahim HM. Levels of Glycosylated Haemoglobin in newly discovered Sudanese Diabetics. Sudan JMS. 2013; 8:9-12.

28. Longo-Mbenza B, Muaka MM, Mbenza G, Mbungu-Fuele S, Mabwa-Mbalanda L, Nzuzi-Babeki V, et al. Risk factors of poor control of HBA1c and diabetic retinopathy: Paradox with insulin therapy and high values of HDL in African diabetic patients. Int J Diabetes \& Metabolism. 2008; 16: 69-78.

29. Koga M, Otsuki M, Matsumoto S, Saito H, Mukai M, Kasayama S. Negative association of obesity and its related chronic inflammation with serum glycated albumin but not glycated hemoglobin levels. Clinica Chimica Acta. 2007; 378:48-52.

30. Habib SS, Aslam M, Hameed W. Gender differences in lipids and lipoprotein (a) profiles in healthy individuals and patients with type 2 diabetes mellitus. Pak J Physiol. 2005; 1.

31. Bakari AG, Onyemelukwe GC, Sani BG, Aliyu IS, Hassan SS, Aliyu TM. Relationship between random blood sugar and body mass index in an African population. Int J Diabetes \& Metabolism. 2006; 14:144-5.

32. Faheem M, Qureshi S, Ali J, Hameed, Zahoor, Abbas F, Gul AM, Hafizullah M. Does BMI affect cholesterol, sugar, and blood pressure in general population?. J Ayub Med Coll Abbottabad. 2010; 22:74-7.

33. Pucarin-Cvetković J, Mustajbegović J, Doko Jelinić J, Senta A, Nola IA, Ivanković D, et al. Body mass index and nutrition as determinants of health and disease in population of Croatian Adriatic islands. Croat Med J. 2006; 47:619-26.

34. Cox-York KA, Sharp TA, Stotza SA, Bessesen DH, Pagliassotti MJ, Horton TJ. The effects of sex, metabolic syndrome and exercise on postprandial lipemia. Metabolism. 2013; 62:244-54.

35. Khan HA, Sobki SH, Khan SA. Association between glycaemic control and serum lipids profile in type 2 diabetic patients: HbA1c predicts dyslipidaemia. Clin Exp Med. 2007; 7:24-9.

36. Mengesha AY. Lipid profile among diabetes patients in Gaborone, Botswana. S Afr Med J. 2006; 96:147-8.

37. Georgopoulos A, Rosengard AM. Abnormalities in the metabolism of postprandial and fasting triglyceride-rich lipoprotein subfractions in normal and insulin-dependent diabetic subjects: Effects of gender. Metabolism. 1989; 38:781-9.

38. Taskinen MR. Diabetic dyslipidaemia: from basic research to clinical practice. Diabetologia. 2003; 46:733-49.

39. Krauss RM. Triglycerides and atherogenic lipoproteins: rationale for lipid management. Am J Med. 1998; 105:S58-S62.

40. Langsted A, Nordestgaard BG. Nonfasting Lipids, Lipoproteins, and Apolipoproteins in Individuals with and without Diabetes: 58434 Individuals from the Copenhagen General Population Study. Clin Chem. 2011; 57:482-9.

41. Jungner I, Marcovina SM, Walldius G, Holme I, Kolar W, Steiner E. Apolipoprotein B and A-I values in 147576 Swedish males and females, standardized according to the World Health Organization-International Federation of 
Clinical Chemistry First International Reference Materials. Clin Chem. 1998; 44:1641-9.

42. Volek JS, Sharman MJ, Gómez AL, DiPasquale C, Roti M, Pumerantz A, et al. Comparison of a Very Low-Carbohydrate and Low-Fat Diet on Fasting Lipids, LDL Subclasses, Insulin Resistance, and Postprandial Lipemic Responses in Overweight Women. J Am Coll Nutr. 2004; 23:177-84.

43. Reznik Y, Morello R, Pousse P, Mahoudeau J, Fradin S. The effect of age, body mass index, and fasting triglyceride level on postprandial lipemia is dependent on apolipoprotein E polymorphism in subjects with non-insulin-dependent diabetes mellitus. Metabolism. 2002; 51:1088-92.

44. Parhofer KG, Barrett PH, Schwandt P. Atorvastatin improves postprandial lipoprotein metabolism in normolipidemlic subjects. J Clin Endocrinol Metab. 2000; 85:4224-30.
45. Karpe F. Postprandial lipemia-effect of lipid-lowering drugs. Atheroscler Suppl. 2002; 3:41-6.

46. Sharrett AR, Ballantyne CM, Coady SA, Heiss G, Sortie PD, Catellier D, et al. Coronary heart disease prediction from lipoprotein cholesterol levels, triglycerides, lipoprotein (a), apolipoprotein A-I and B, and HDL density subfractions. The Atherosclerosis Risk in Communities (ARIC) Study. Circulation. 2001; 104:1108-13.

47. Talmud PJ, Hawe E, Miller GJ, Humphries SE. Non-fasting apolipoprotein $\mathrm{B}$ and triglyceride levels as a useful predictor of coronary heart disease risk in middle-aged UL men. Arterioscler Thromb Vasc Biol. 2002; 22:1918-23. 